\title{
THE STRUCTURE OF THE TERMINAL FILAMENT, THE OVARIOLE SHEATH AND THE OVIDUCT MUSCULATURE OF THE COLORADO BEETLE (LEPTINOTARSA DECEMLINEATA SAY, 1824)
}

\author{
by \\ H. A. AKSTER \\ Department of Experimental Animal Morphology and Cell Biology, Agricultural University, Wageningen, \\ The Netherlands
}

$\&$

\author{
W. A. SMIT \\ Zoological Laboratory, University of Amsterdam, The Netherlands
}

\begin{abstract}
In the Colorado Beetle, the terminal filament cells resemble the epidermal cells which connect muscle cells with the cuticle, the so-called tendon cells. They contain many microtubules which have projections interconnecting them. The microtubules are also connected by these projections to desmosomes.

The tunica propria is a basement membrane-like layer of low elasticity. It separates the terminal filament from the germarium. The outer ovariole sheath is a muscle sheath which is continuous with the muscle sheath around the oviducts. The whole muscle sheath consists of a monolayer network. Sarcolemmal invaginations at the $I$ band and at the $Z$ line probably form part of one $T$ system. The cuticle of the common oviduct has scales with long caudally directed spines.

The rostral attachment of the muscle sheath corresponds to the existing descriptions of tendon cells. The attachment of the muscle sheath to the cuticle of the common oviduct is different.
\end{abstract}

\section{INTRODUCTION}

The terminal filament in insects connects the germarium to the body wall or to the dorsal phragma. Attachment to the fat body is also mentioned (Imms, 1970; Snodgrass, 1935). The pedicel passes into a lateral oviduct. Both lateral oviducts join the common oviduct, which is of ectodermal origin and has a cuticular lining.

The ovariole is surrounded by two sheaths. Directly against the ovariole lies the tunica propria. This sheath is described as a basement membrane (Imms, 1970) or as an elastic membrane containing fine fibrils (Bonhag \& Arnold, 1961; Chapman, 1969). On the outside lies the outer ovariole sheath. Imms (1970) and Snodgrass (1935) use the name peritoneal sheath for this layer. The outer ovariole sheath, which is separated from the tunica propria by an intervening space, is described as a connective tissue sheath or as modified fat tissue.

In many insects this sheath consists of a maze of muscle fibers. It contains also tracheoles (Imms, 1970; Snodgrass, 1935; Chapman, 1969). In preparations of Colorado Beetles, contractions were observed in the terminal filament and in the ovariole wall (Companjen \& De Wilde, pers. comm.). Since it is possible that such contractions have a function in the transport of eggs from the ovariole into the oviduct, the structures of the terminal filament and the ovariole sheaths and the structure of the oviduct musculature have been investigated. 


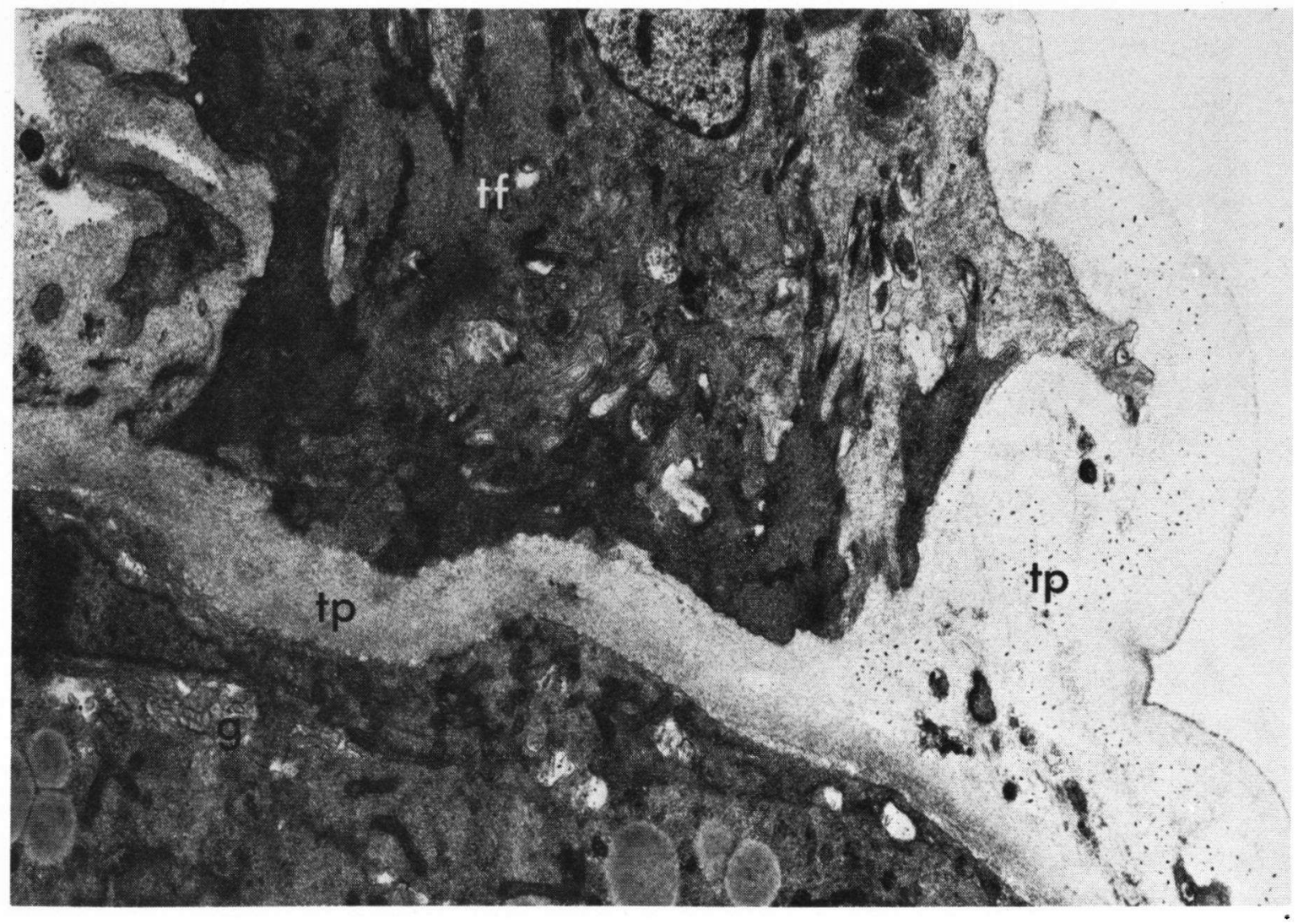

Fig. 1. Longitudinal section of the terminal filament-germarium border. The terminal filament is always separated from the ovariole by a ca. $1 \mu \mathrm{m}$ strip of tunica propria. $10500 \times$.

$\mathrm{g}=$ germarium; $\mathrm{tf}=$ terminal filament; $\mathrm{tp}=$ tunica propria.

\section{MATERIAL AND METHOD}

In cooled and decapitated Colorado Beetles the organs were fixed in situ for 15 minutes. After dissection, fixation was continued for 1 hour. From some non-cooled animals the ovarioles were removed before fixation, allowing the muscle fibers to contract in the fixative.

The fixative was a $2.5 \%$ glutaraldehyde solution containing $0.25 \mathrm{M}$ sucrose, buffered with 0.05 M cacodylate ( $\mathrm{pH}$ 7.4). After thorough rinsing in a cacodylate buffer containing $0.34 \mathrm{M}$ sucrose, the tissue was postfixed with a veronal acetate buffered $1 \%$ osmium tetroxide solution for 1 hour. After 30 minutes in an aqueous solution of uranyl acetate followed by dehydration in ethanol, the tissue was embedded in Epon 812.

Ultrathin sections and $1 \mu \mathrm{m}$ sections were cut with glass knives on a Reichert ultramicrotome.

The ultrathin sections were stained, first with saturated uranyl acetate and then with a lead citrate solution. These sections were studied with a Zeiss EM 9 electron microscope.

The $1 \mu \mathrm{m}$ sections were stained with a $1 \%$ toluidine blue solution containing $1 \%$ borax. Light microscopic photographs were made with a Zeis II photomicroscope and with a Wild polarizing microscope.

\section{RESULTS}

\section{The terminal filament}

\section{Position.-}

In the Colorado Beetle the cranial site of attachment of the terminal filament is the phragma between meso- and metathorax. The terminal filament cells are caudally separated from the germarium by a ca. $1 \mu \mathrm{m}$ strip of tunica propria (figs. 1, 11). 


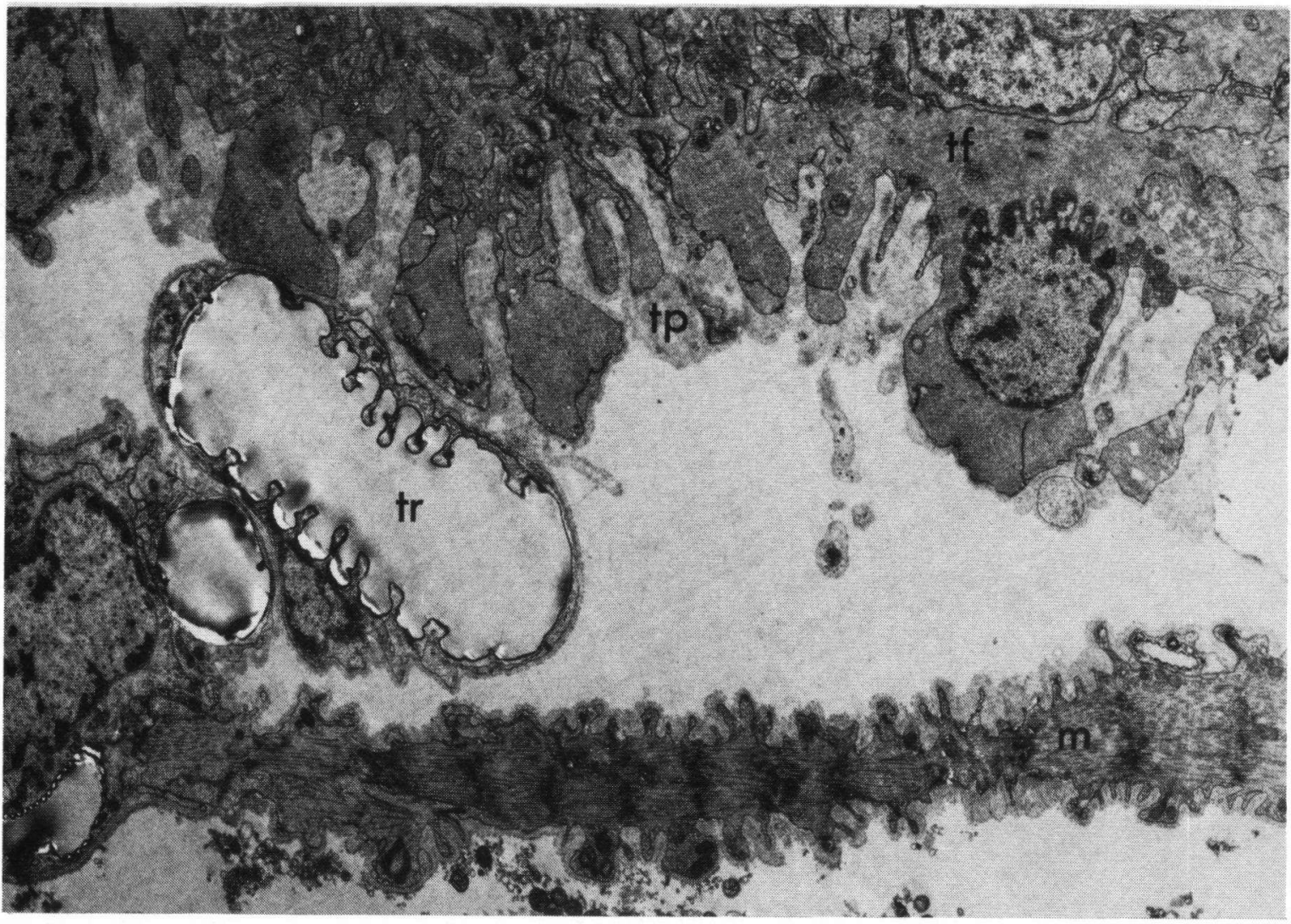

Fig. 2. Longitudinal section of a contracted terminal filament and outer ovariole sheath. Large terminal filament projections protrude into the tunica propria. $7200 \times$.

$\mathbf{m}=$ muscle $; \mathrm{tf}=$ terminal filament; $\mathrm{tp}=$ tunica propria; $\mathrm{tr}=$ tracheole.

In the first part, craniad of the germarium, the terminal filaments from the different ovarioles lie free from each other. More craniad they join into a left and a right bundle. Each terminal filament remains surrounded by its own ovariole sheaths. The outer ovariole sheaths do not fuse. There is no extra sheath surrounding the whole bundle. Both bundles split, half of each bundle runs underneath the dorsal vessel to the opposite bodyhalf and joins the remaining half of the other bundle for attachment to the phragma.

\section{Structure. -}

The terminal filament consists of long slender cells that run parallel to its longitudinal axis. In stretched terminal filaments the long borders of the cells are relatively smooth (fig. 3). At the short borders the cells interdigitate.

In contracted terminal filaments the cells also interdigitate at the long borders. In this case all cell borders are irregular and large terminal filament projections protrude into the tunica propria (fig. 2).

Many intercellular spaces occur between the terminal filament cells. These are filled with an amorphous substance. Contiguity between the intercellular spaces and the tunica propria was not found. One of the many desmosomes (maculae adhaerentes) and gap junctions that are present in the cell borders are always observed between the intercellular spaces and the tunica propria. The dark line in the middle of the desmosome intercellular space has connections with the outer lamina of the cell membrane. Along the intercellular spaces many hemidesmosomes are observed. At some places division of desmosomes into two hemidesmosomes can be seen. The dark line in the middle of the desmosome also splits, both halves following a hemidesmosome along the receding cell borders (fig. 

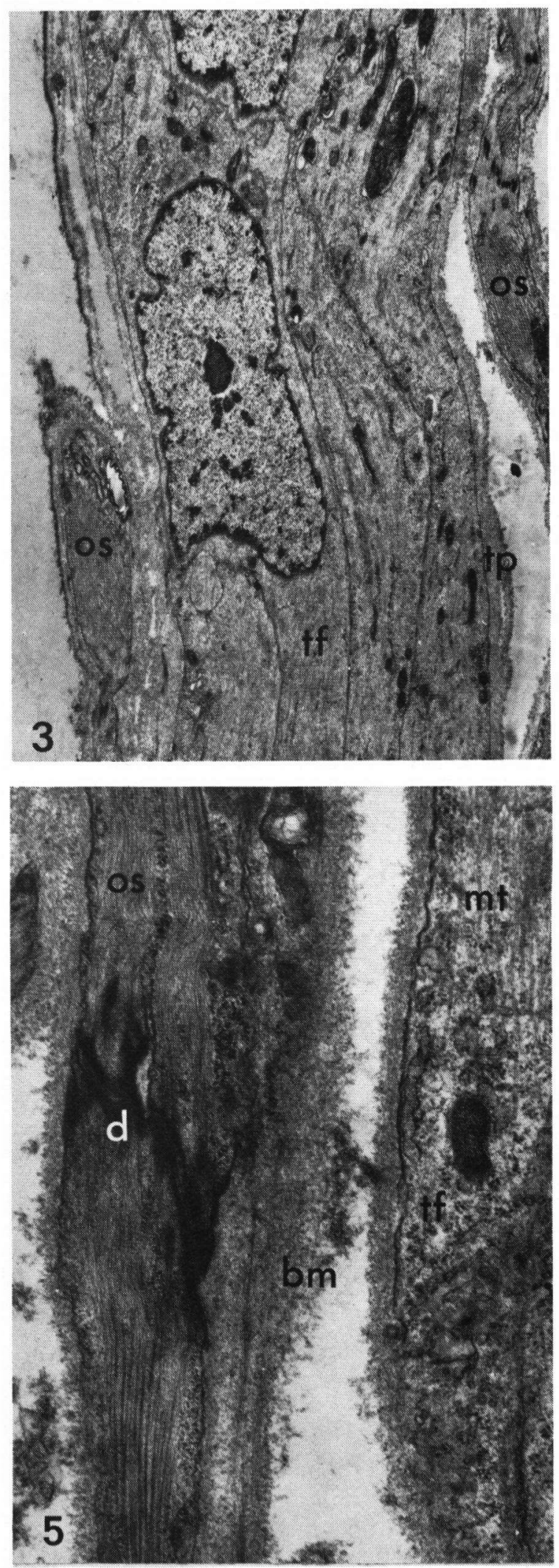

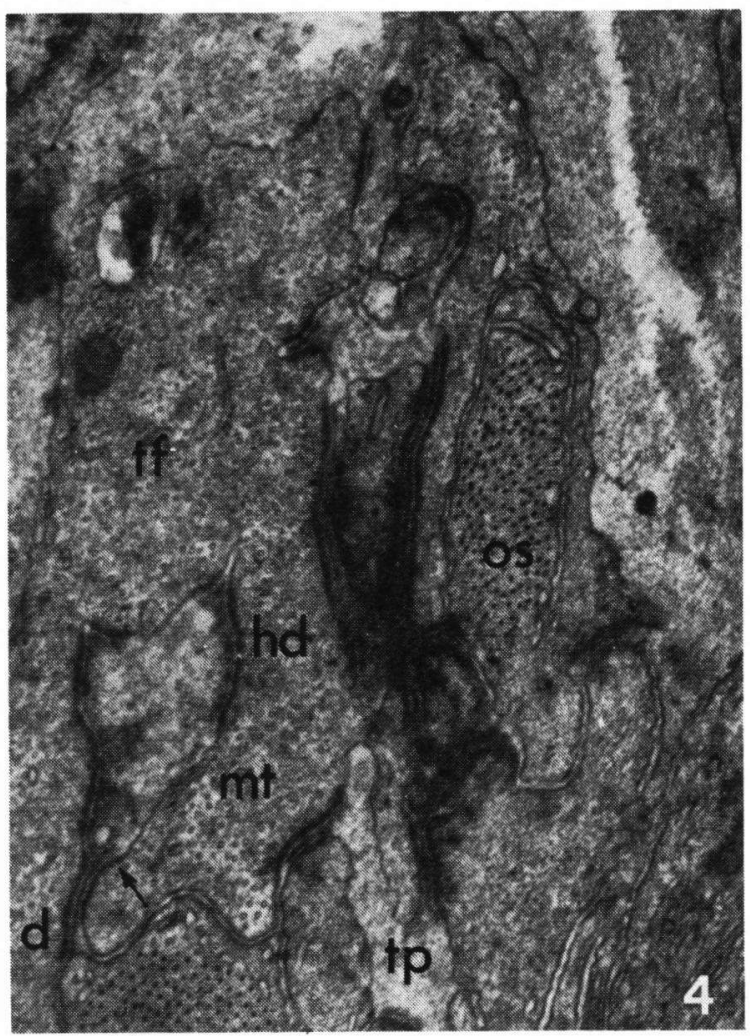

Fig. 3. Detail of a non-contracted terminal filament and outer ovariole sheath, longitudinal section. The terminal filament consists of long slender cells. The long borders of the cells are smooth. The outer ovariole sheath is a muscle layer with adjacent tracheoles. $9000 \times$.

Fig. 4. Terminal filament and outer ovariole sheath, transverse section. The terminal filament cells contain many microtubules. The intercellular spaces between the terminal filament cells are always separated from the tunica propria by desmosomes. The division of a desmosome into two hemidesmosomes is observed (arrow). The dark line in the middle of the desmosome also splits. In this preparation a part of the tunica propria is missing, resulting in a direct contiguity between the tunica propria and the outer ovariole sheath. $33000 \times$.

Fig. 5. Detail of a non-contracted terminal filament and outer ovariole sheath, longitudinal section. The border between the muscle cells of the outer ovariole sheath consists of desmosomes. The long borders of the terminal filament cells are smooth. The cells contain many microtubules. $24000 \times$.

bm = basement membrane; $d=$ desmosomes; hd $=$ hemidesmosomes; $\mathrm{mt}=$ microtubules; os = outer ovariole sheath; $\mathrm{tf}=$ terminal filament; $\mathrm{t} \mathrm{p}=$ tunica propria. 


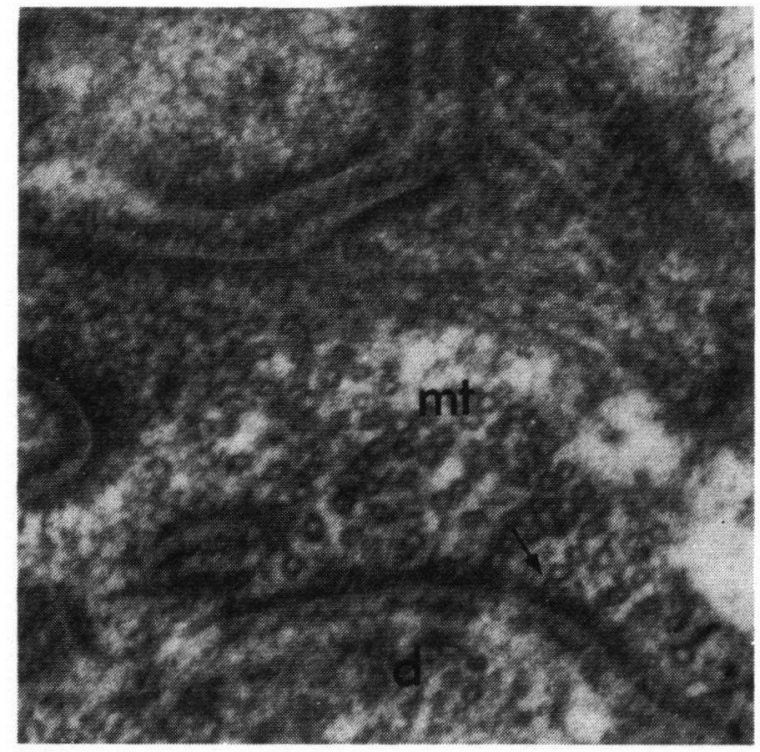

Fig. 6. Transverse section of the terminal filament-epidermis border. The microtubules are connected by their projections. These projections also connect microtubules to the (hemi)desmosomes (arrow). $90000 \times$.

$\mathrm{d}=$ desmosomes; $\mathrm{mt}=$ microtubules.

4). This is also observed along the tunica propria. In various places along the tunica propria, dark desmosome-like material lies against the cell membrane (fig. 4).

The most striking feature of the terminal filament cells is the great number of microtubules running parallel to their longitudinal axes (figs. 4, 5). The microtubules have interconnecting projections. These projections also connect the microtubules to the desmosomes. These desmosomes run parallel to the microtubules (fig. 6). Between the bundles of microtubules some other organelles are visible, but most of them, including the nucleus, are found at the periphery of the cell. The nuclei are oblong and somewhat indented. Smooth and rough endoplasmic reticula are scanty but there are numerous free ribosomes. There is an obvious Golgi complex. The cells contain multivesicular bodies and other lysosomes.

Attachment to the phragma. -

The border between the terminal filament cells and the epidermal cells of the phragma is interdigitated. These cells adjoin only over a part of their digitations. Here the cell walls consist mostly of desmosomes; some gap junctions can be seen. The remaining parts of the cells are separated by large intercellular spaces that are continuous with the tunica propria. This is in contrast to the intercellular spaces in the terminal filament proper. Both in the terminal filament cells and in the epidermal cells, hemidesmosomes occur along the intercellular spaces (figs. 7 A-C, 8).

The epidermal cells to which the terminal filament is attached have the same structure as epidermal cells that connect muscles with the cuticle, the so-called tendon cells. These cells contain a large number of microtubules. At the apical side there are many finger-like cuticular invaginations. On two sides these invaginations are lined with hemidesmosomes. In the invaginations a rod connected to the outer lamina of the cell membrane is visible (fig. 7B).

The microtubules run parallel with the hemidesmosomes and are connected to them by means of their projections (figs. $7 \mathrm{~A}-\mathrm{C}, 8$ ). This microtubule-desmosome connection has been described already (Akster \& Smit, 1975).

\section{The tunica propria}

The tunica propria is a basement membrane-like layer containing fibrils. It is continuous with the basement membrane of the epidermis of the phragma. In places where the outer ovariole sheath is close to the terminal filament, the basement membrane of this sheath and the tunica propria fuse. Absence of the tunica propria, resulting in a direct contiguity between the terminal filament and the outer ovariole sheath, has been observed only once (fig. 4).

Mostly an open space in which haemocytes occur is present between the tunica propria and the outer ovariole sheath. The tunica propria contains grana and bundles of thin electrondense fibrils, running parallel to the long axis of the terminal filament. In the strip of tunica propria between the terminal filament and the germarium (fig. 11) some fibrils with collagen banding are present.

In preparations of contracted terminal filaments, the tunica propria is folded in long loops around the terminal filament (fig. 9).

\section{The outer ovariole sheath}

The outer ovariole sheath consists of a muscle network with adjacent tracheoles (fig. 10). These 

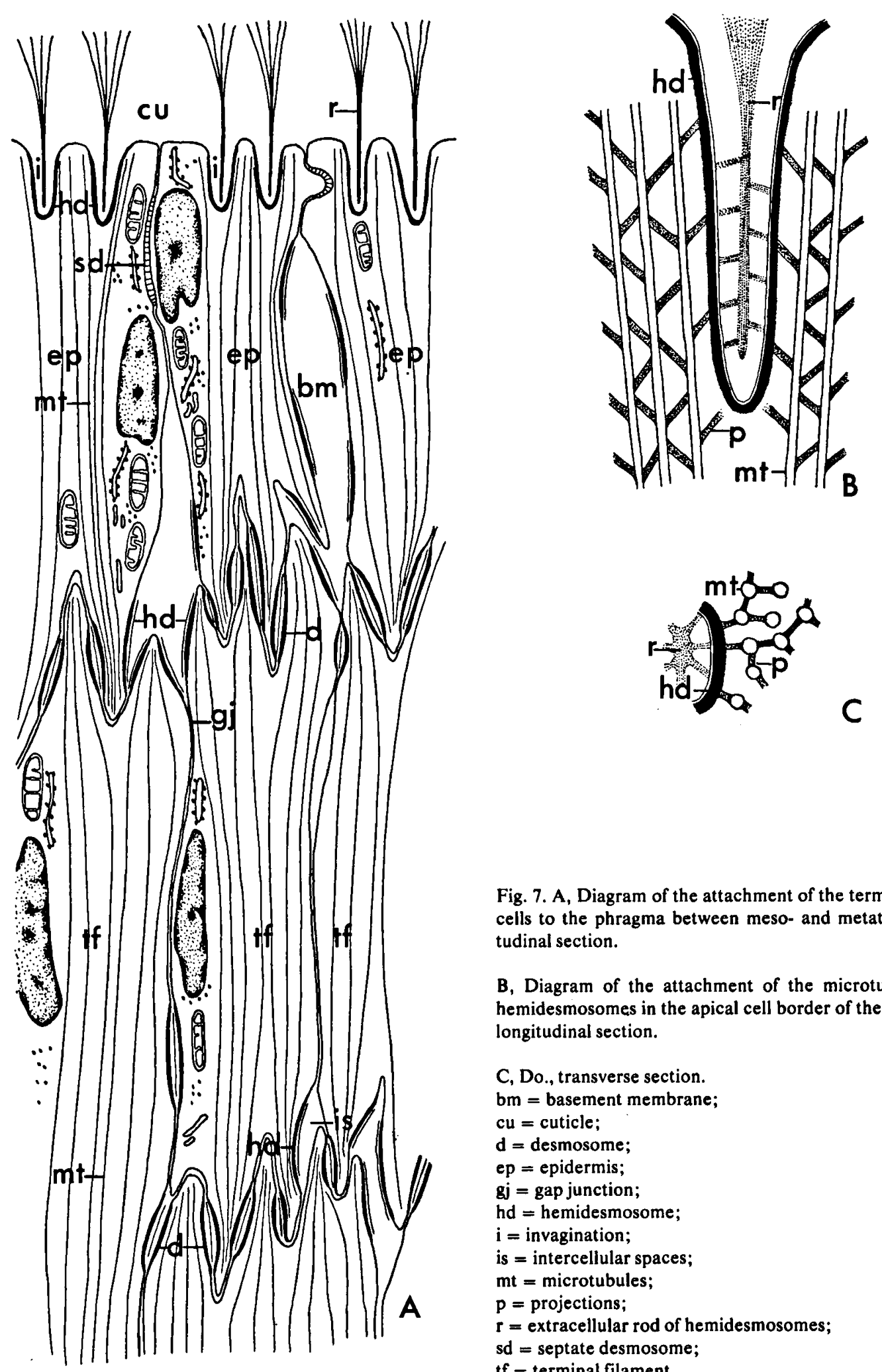

Fig. 7. A, Diagram of the attachment of the terminal filament cells to the phragma between meso- and metathorax, longitudinal section.

B, Diagram of the attachment of the microtubules to the hemidesmosomes in the apical cell border of the tendon cells, longitudinal section.

C, Do., transverse section.

bm = basement membrane;

$\mathrm{cu}=$ cuticle;

d = desmosome;

ep = epidermis;

gj = gap junction;

hd = hemidesmosome;

$\mathrm{i}=$ invagination;

is = interceliular spaces;

$\mathrm{mt}=$ microtubules;

$\mathrm{p}=$ projections;

$\mathbf{r}=$ extracellular rod of hemidesmosomes;

sd = septate desmosome;

tf $=$ terminal filament. 


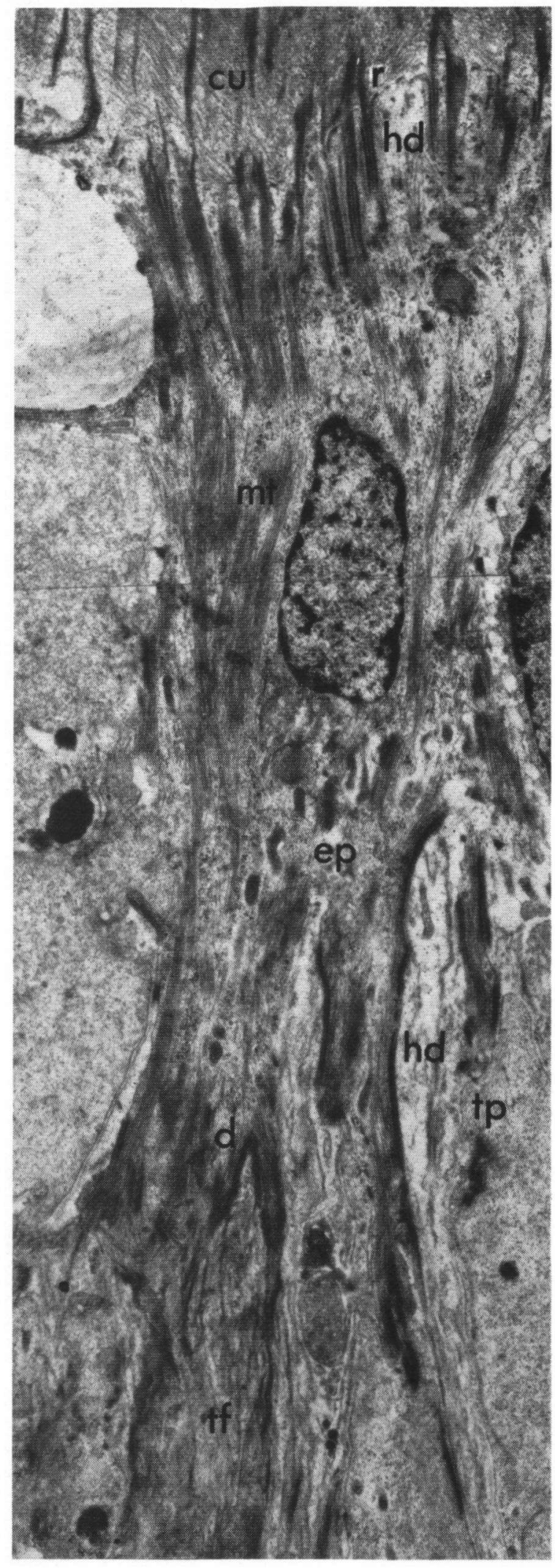

tracheoles are restricted to the outer ovariole sheath. Between the terminal filament cells no tracheoles are visible. Most muscle cells are about $8 \mu \mathrm{m}$ thick, but diameters up to $22 \mu \mathrm{m}$ are observed as well. The borders between the muscle cells interdigitate; they consist of desmosomes.

The tendon cells of the outer ovariole sheath are much longer than the tendon cells of adjacent skeletal muscles. The outer ovariole sheath is continuous with the muscle layer of the oviduct.

\section{The oviduct musculature}

The oviduct musculature is a muscle network, continuous with the outer ovariole sheath. Adjacent to the oviduct lies a layer of relatively thick fibers (diameter 12-28 $\mu \mathrm{m}$ ). From this sheath a layer of thinner fibers (diameter 4-12 $\mu \mathrm{m}$ ) branches off (figs. 12, 13). The orientation of the muscle fibers of both layers runs mainly parallel to the longitudinal axis of the oviduct. As in the outer ovariole sheath, the borders between the muscle cells are interdigitated and consist of desmosomes.

The nuclei are subsarcolemmal. Mitochondria, ribosomes, tubules of the endoplasmic reticulum, and some microtubules running parallel with the myofilaments, are observed around the nucleus. Mitochondria are also visible next to the I band. Ribosomes may occur in this place.

The myofibrils are incompletely separated by the sarcoplasmic reticulum. There are $9-11$ actin filaments round each myosin filament. The ratio actin/myosin is ca. $6: 1$. The $Z$ line is irregular. The $\mathrm{H}$ band is indistinct.

At some places on $Z$ line level and on I band level, large membrane invaginations are apparent

Fig. 8. Epidermal cell connecting a terminal filament cell to the cuticle, longitudinal section. The terminal filamentepidermis border is interdigitated and consists for the main part of long desmosomes. Large tunica propria invaginations are present. Along the invaginations of the tunica propria, hemidesmosomes occur. In the apical border of the cell, finger-like membrane invaginations occur. Along these invaginations, hemidesmosomes are observed. The dark rod in the invaginations protrudes deep into the cuticle. $13500 \times$. $\mathrm{cu}=$ cuticle; $\mathbf{d}=$ desmosome; $\mathrm{ep}=$ epidermis; $\mathrm{hd}=$ hemidesmosome; $\mathrm{mt}=$ microtubules; $\mathrm{r}=$ extracellular rod of hemidesmosomes; tf = terminal filament; $t p=$ tunica propria. 
(arrows in figs. 14, 15). These invaginations may taper into the thinner membrane invaginations of the $T$ system. The $T$ tubules may also originate abruptly from the large membrane invaginations. $T$ tubules not arising from invaginations, but directly from the cell surface, are also observed. This takes place in the $I$ band, in the $Z$ line and in myofilamentless cytoplasm. The direction of the $T$ tubules can be both transversal and longitudinal. The diad is at the $A / I$ junction. The diameter of the $T$ tubules in this place is $300-400$ $\AA$. At the point where the membrane invaginations cross a $\mathbf{Z}$ line, a desmosome is observed. This applies both to the large membrane invaginations and to the $T$ tubules proper. These desmosomes are ca. $800 \AA$ wide. The membrane thickening belonging to the desmosome continues for a short distance along the I band. Desmosome-like membrane thickenings are also observed on $\mathrm{Z}$ line level on the surface of the cell.

The desmosomes are not only present on the cell surface but they are also observed deeper in the cell. In this case the T tubules are widened $(>1000 \AA$ ) on both sides of the desmosome.

In contrast to the richly tracheolated outer ovariole sheath, the oviduct musculature contains few tracheoles. Between the cells of the oviduct epithelium some tracheoles are observed as well.

Endplates are sporadic at the caudal end of the oviduct musculature. In the outer ovariole sheath endplates are absent.

\section{The oviduct epithelium}

In some places along the common oviduct, the muscle sheath is attached to the oviduct epithelium over short stretches. The epithelium cells here have long thin processes. Some of these are attached to the muscle cells by means of short desmosomes. Two hemidesmosomes separated

Fig. 9. Longitudinal section of a contracted terminal filament and tunica propria. The tunica propria is folded in long loops. $16000 \times$.

Fig. 10. The outer ovariole sheath along the terminal filament and the upper part of the germarium. The outer ovariole sheath consists of a muscle network with adjacent tracheoles. Phase contrast, $220 \times$.

$g=$ germarium; os = outer ovariole sheath; $t$ f = terminal filament; $t \mathrm{p}=$ tunica propria; $\mathrm{tr}=\mathrm{tracheole}$.
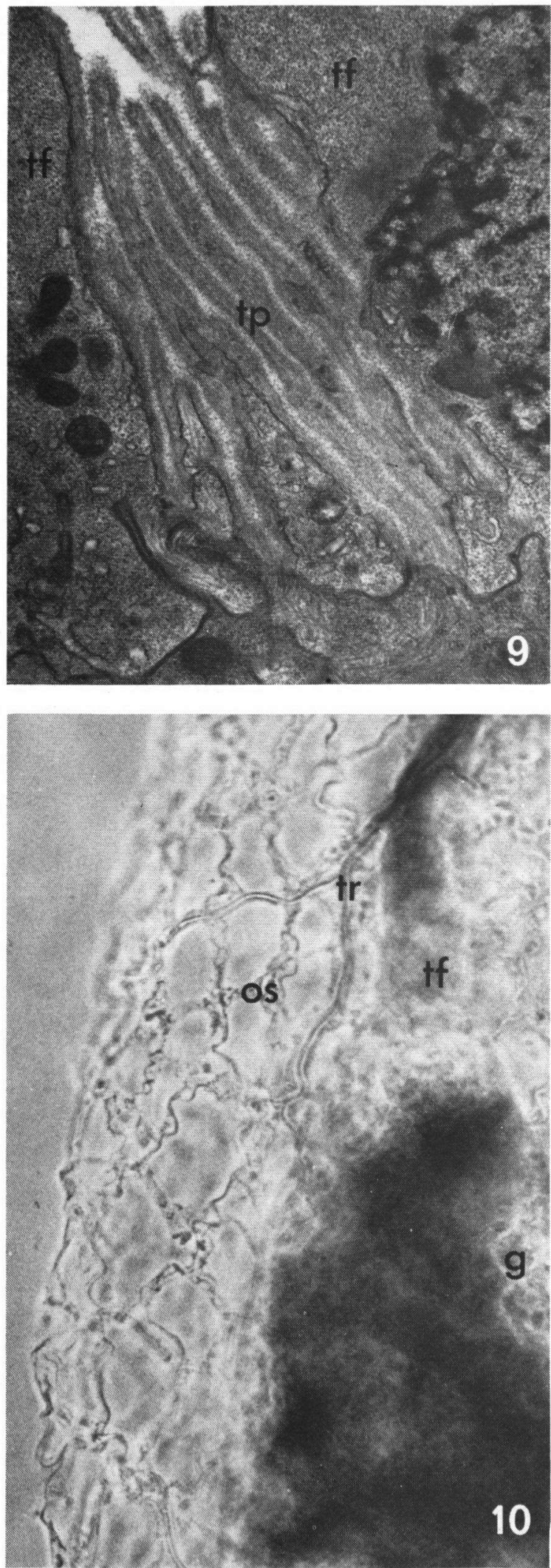


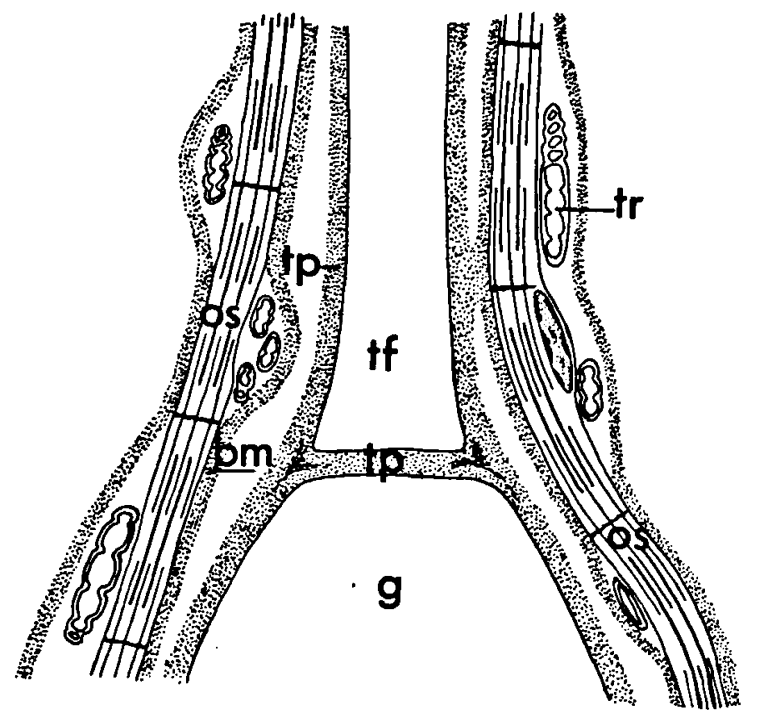

Fig. 11. Diagram of the terminal filament-germarium connection, longitudinal section.

bm = basement membrane; $\mathbf{g}=$ germarium; os = outer ovariole sheath; tf = terminal filament; $t p=$ tunica propria; tr $=$ tracheole.

by a strip of basement membrane are also observed (figs. 16, 17). The desmosomes and hemidesmosomes are much smaller than those observed at the place where the terminal filament and the outer ovariole sheath are attached to the phragma between meso- and metathorax. The interdigitated muscle-epithelium border is not present along the oviduct.

In several places in the muscle cells as well as in the epithelium cells, the cell membrane has a desmosome-like thickening. This is also observed in the terminal filament cells and along the lateral oviducts. However, a dark extracellular line as present in desmosomes is not seen in combination with these thickenings.

The cuticle of the common oviduct forms scales that bear long caudally directed spines (fig. 12). Inside these spines, projections of the epithelium cells are present. Along the cuticle, these cells have many narrow, parallel anastomosing membrane invaginations (figs. 17, 18). Some of these invaginations widen at their tops. Here the membrane shows a desmosome-like thickening, but a dark line is absent.

Microtubules run through the cell from the muscle-epithelium border to the cuticle. These microtubules have projections. Attachment of these projections to the cell membrane in the oviduct epithelium is less obvious than in the tendon cells described above. This is due to the great number of other organelles present in the cells of the oviduct epithelium. The great number of mitochondria is particularly striking. Between the membrane invaginations, mitochondria are not observed. These areas contain only few organelles. The cells have an extensive rough endoplasmic reticulum and many free ribosomes. They contain more than one Golgi complex. The cells have vesicles with a diameter of ca. $450 \AA$. These vesicles have projections. They lie in groups in cell areas where few other organelles are seen. Most of them lie at the muscle side of the cell.

\section{DISCUSSION}

\section{The terminal filament}

The structure of the terminal filament cells resembles the structure of the epidermal cells to which the terminal filament is attached. This cell type, characterized by many microtubules which are attached apically and basally to desmosomes, has often been described. These descriptions concern mostly cells that constitute the muscle-cuticle connections of insects and other arthropods (Auber, 1963; Lai-Fook, 1967; Koulish, 1973). In some cases this structure occurs in epidermal cells to which no muscles are attached (Noirot-Thimothée \& Noirot, 1966; Moulins, 1968).

Points of difference between the terminal filament cells and the epidermal cells are: (a) at the borders between the terminal filament cells no septate desmosomes are observed in contrast to the borders between the epidermal cells, and (b) the intercellular spaces on the basal epidermis border are continuous with the tunica propria, but desmosomes are always observed in the connections between the intercellular spaces in the terminal filament and the tunica propria.

The great resemblance between the terminal filament cells and the epidermal cells suggests a relationship. The fact that the terminal filament is likewise separated from the remainder of the ovariole by a strip of tunica propria, supports this suggestion. 


\section{The tunica propria}

According tot Ashurst (1968) the insect connective tissue, excepting the connective tissue around the central nervous system, is part of a basement membrane. This basement membrane is continuous throughout the insect. Ashurst (op. eit.) discerns 3 different structures: (1) connective tissue without fibrils, (2) connective tissue with thin unbanded fibrils, (3) connective tissue with obvious collagen fibrils.

In the tunica propria both unbanded thin fibrils and collagen fibrils are observed. According to Ashurst (1968) it is more probable that this connective tissue is produced by the underlying cells, than by haemocytes. According to King et. al. (1968) the tunica propria around the ovarioles of Drosophila melanogaster is not produced by the underlying cells, but by cells migrating from apical to basal along the developing ovariole. However, King et al. (op. cit.) do not describe a strip of tunica propria situated between the terminal filament and the germarium. On the other hand, Truckenbrod (1970) does describe this strip in the termite Kalothermes flavicollis.

It is conceivable that such a strip should be produced by adjacent cells rather than by haemocytes. This applies even stronger to the material in the intercellular spaces of the terminal filament, because desmosomes are always observed between these spaces and the tunica propria. The terminal filament cells have no extensive endoplasmic reticulum, but there are many free ribosomes present and there is an obvious Golgi complex. Secretion vacuoles are not observed.

Fig. 12. The epidermis and the muscle sheath of the common oviduct, longitudinal section. Cuticular scales protrude into the lumen of the oviduct. These scales bear long caudally directed spines. The thin muscle layer is continuous with the thicker layer close to the oviduct. In places where no muscle is attached, the borders of the epidermal cells are relatively smooth (one arrow). These borders are very irregular in places where the muscle is attached (two arrows). On the borders between the muscle cells desmosomes occur. $250 \times$.

Fig. 13. Polarizing microscope photograph of the unfixed muscle sheath of the common oviduct. The muscle sheath consists of a monolayer network. The muscle fibers are mainly oriented parallel to the longitudinal axis of the oviduct (indicated by the arrow). $100 \times$.

ep = epidermis; $d=$ desmosome; $m=$ muscle; $s c=$ scales; $\mathrm{sp}=$ spine.
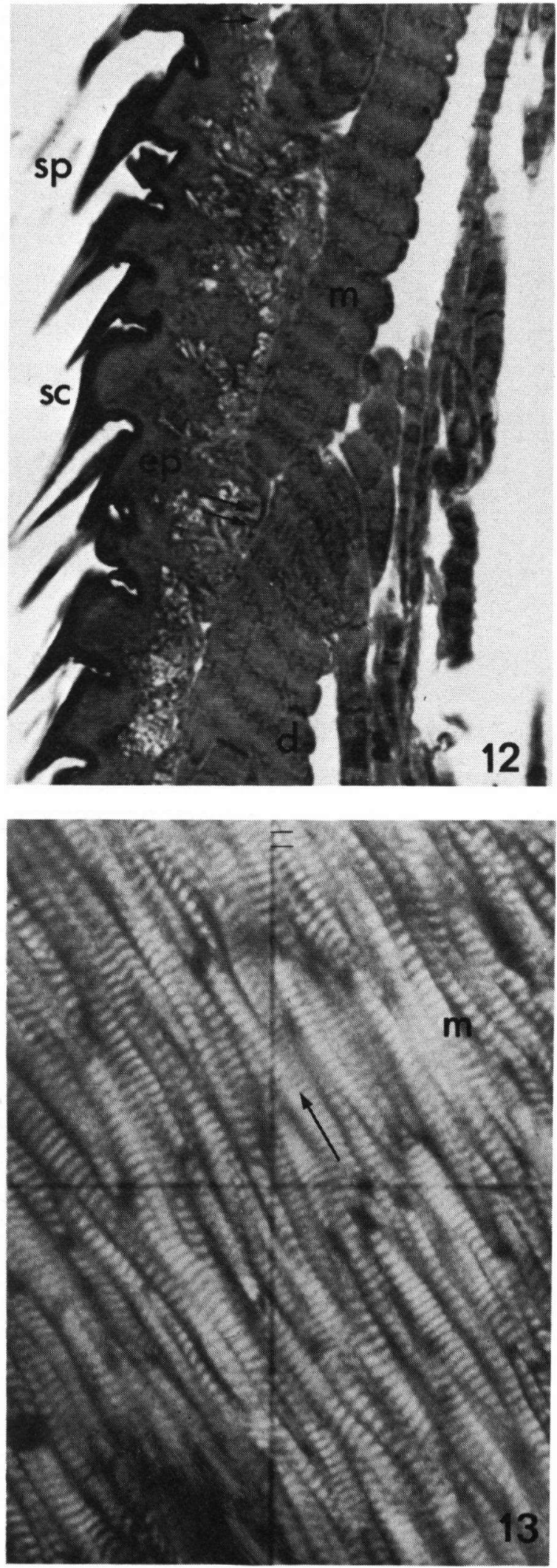

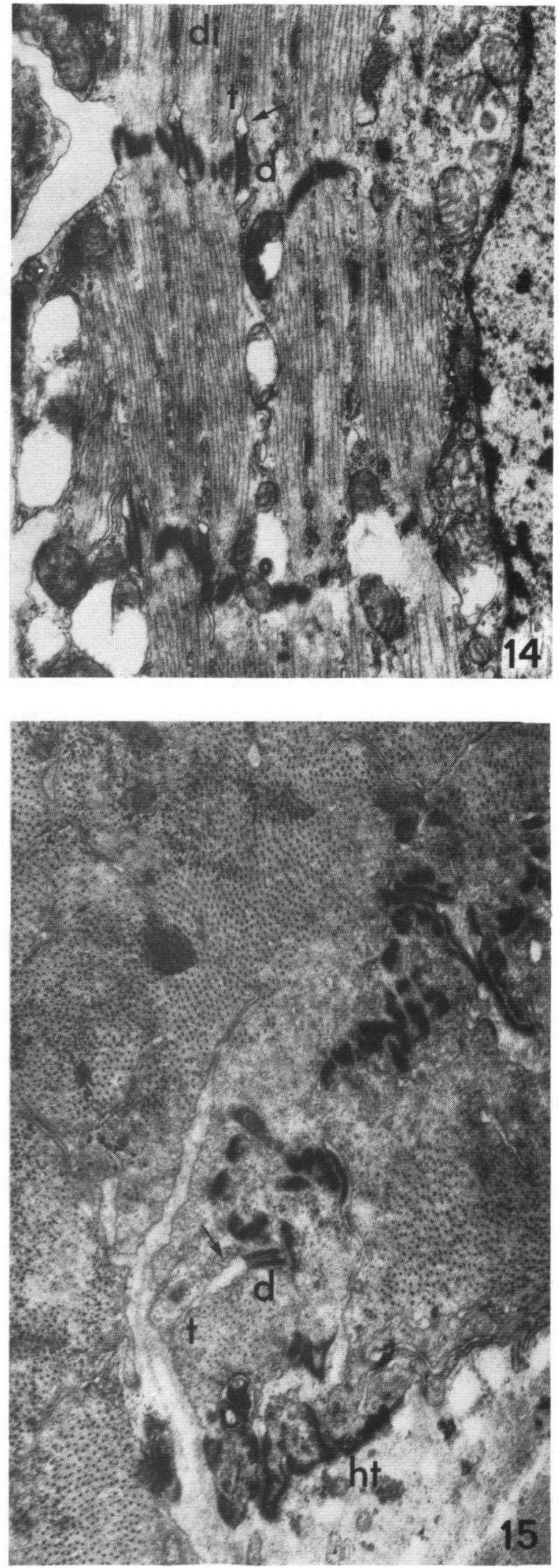

The elastic ovariole sheath of Periplaneta americana, as described by Bonhag \& Arnold (1961) and quoted by Chapman (1969), stretches during the vitellogenesis. After the oocyte has moved up, this tunica propria contracts.

However, in the Colorado Beetle it is improbable that the tunica propria is very elastic. In terminal filament preparations which were not stretched during fixation, the tunica propria is folded in long loops around the terminal filament (fig. 9). The outer ovariole sheath and the terminal filament probably have a better contractility than the tunica propria.

Von Hehn (1967) describes the fused basement membranes of muscle sheaths and oviduct epithelium in the oviduct of the stick insect Carausius morosus as the only structures capable of transmitting muscle contractions.

In Colorado Beetle oviduct preparations, the basement membrane of the muscle sheath also fuses with the basement membrane of the oviduct epithelium in some places. Along the lateral oviduct this is the only connection between muscle sheath and oviduct. Along the common oviduct, desmosomes and hemidesmosomes are present as well. If fused basement membranes transmit muscle contractions, these layers must be inelastic. It would be strange if the tunica propria, which is continuous with one of these layers, should show considerable tensibility under the muscle stresses produced. Moreover, the presence of an elastic strip of tunica propria between terminal filament and ovariole would hinder the transport of ova from the ovariole to the oviduct. Another argument for an inelastic tunica propria is the fact that, besides desmosomes, two hemidesmosomes separated by a strip of tunica propria, are present in the muscleepidermis and in the terminal filament-epidermis border. Sometimes the continuation of a desmo-

Fig. 14. The muscle sheath of the common oviduct, longitudinal section. Membrane invaginations of variable diameter are observed on $Z$ line and on $I$ band level. Where the membrane invaginations cross a $\mathrm{Z}$ line, a desmosome is seen. The membrane thickening continues for a short distance along the I band. The invaginations widen (arrow) on both sides of the desmosome. The diad occurs at the A-I junction. $18000 \times$.

Fig. 15. Do., transverse section. $23300 \times$.

$\mathrm{d}=$ desmosome $\mathrm{di}=$ diad; $\mathrm{t}=$ tubules; $\mathbf{h t}=$ hemidesmosome-like thickening. 


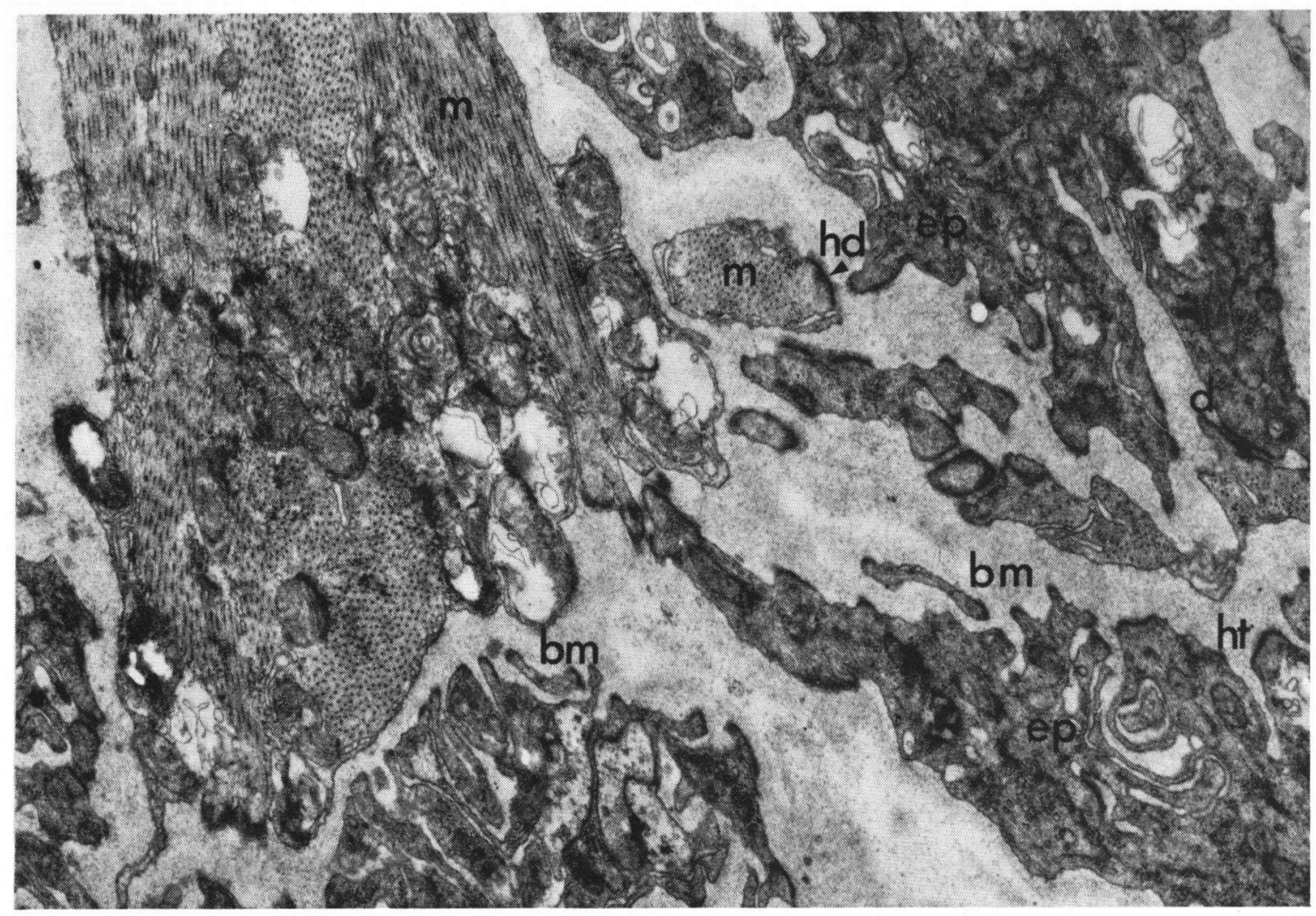

Fig. 16. Between the muscle cells and the epidermal cells of the common oviduct, short desmosomes and short hemidesmosomes, separated by basement membrane, are present. Transverse section, $18000 \times$.

bm = basement membrane; $d=$ desmosome; ep = epidermis; hd = hemidesmosome; $h t=$ hemidesmosome-like thickening; $\mathrm{m}=$ muscle.

some into two hemidesmosomes is observed. This suggests that both desmosomes and hemidesmosomes separated by a strip of tunica propria, serve as a structure of attachment to the muscle. This implies that, in the Colorado Beetle, the tunica propria must be relatively inelastic.

\section{The muscle sheath}

In the Colorado Beetle the outer ovariole sheath and the oviduct musculature form a continuous network. The orientation of the fibers of this network is parallel with the longitudinal axis of the ovariole for the main part. When the ovariole sheath contracts, the terminal filament shortens (fig. 2), thus possibly pulling up the entire ovariole and assisting in the transport of the eggs. Since the wall of the ovariole consists of prominent scales connected by receding parts, the oviduct will widen easily when the egg passes.
The scales with their caudally directed spines will prevent rebounding of the eggs. Since the oviduct musculature is a network, it can dilatate with the widening movement of the oviduct. In order to transport the eggs, contraction waves from rostral to caudal through the oviduct would be expected. But endplates are only seen in the caudal part of the oviduct and then but sporadicly. The connections between the muscle cells consist of desmosomes. Cell-to-cell connections as maculae occludentes or septate desmosomes, which are held capable of transmitting impulses, are not observed.

In the oviduct musculature of Carausius morosus endplates are not found either (Von Hehn, 1967). In this animal there are three separate muscle networks around the oviduct. The inner and outer sheaths give the impression of longitudinal muscles. The middle sheath is more like a transverse muscle layer. These 


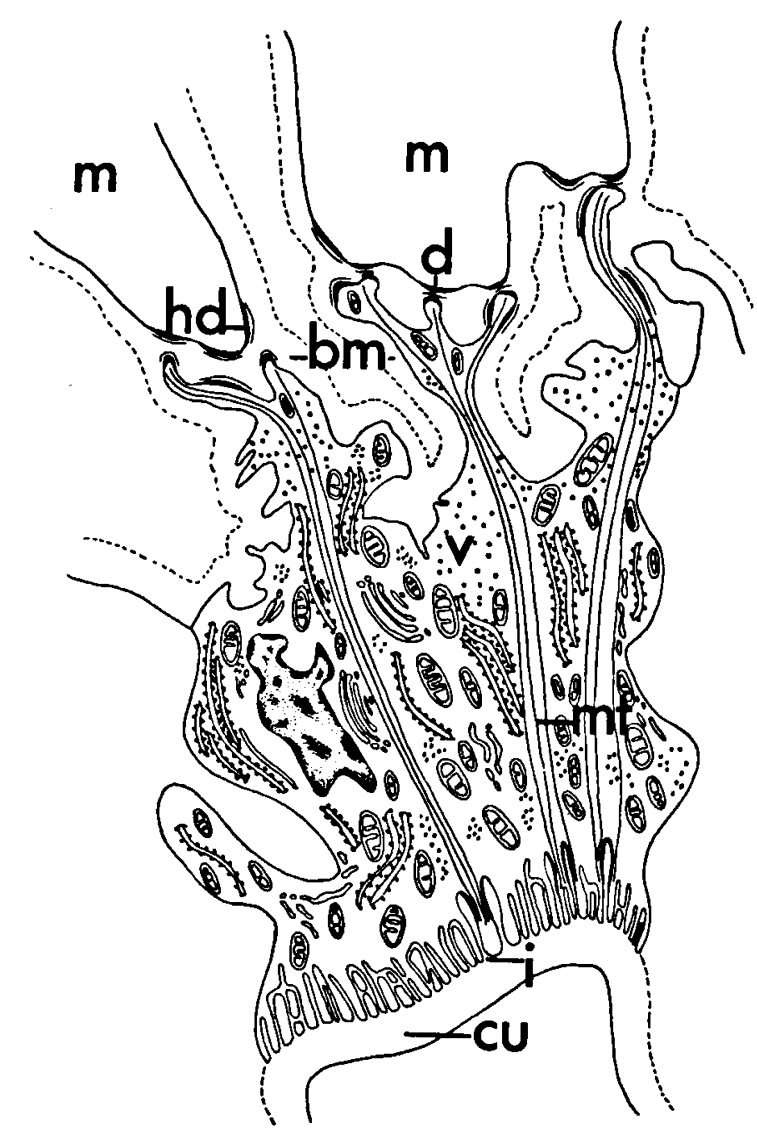

Fig. 17. Diagram of an epidermal cell of the common oviduct to which muscle is attached, transverse section.

bm = basement membrane; $\mathrm{cu}=$ cuticle; $\mathrm{d}=$ desmosome; hd $=$ hemidesmosome; $\mathrm{i}=$ membrane invaginations; $\mathrm{m}=$ muscle; $\mathrm{mt}=$ microtubules; $\mathrm{v}=$ vesicles.

muscles have also intercalated cell borders consisting of desmosomes.

The muscle cells have the features of a slow arthropod muscle (Smith et al., 1966; Jahromi \& Atwood, 1967; Toselli \& Pepe, 1968): an irregular $\mathrm{Z}$ line and $\mathrm{H}$ band and an actin filament/myosin filament ratio of $6: 1$.

As regards insects and crustaceans, descriptions of two types of $T$ tubules exist. Firstly, the T system proper, sometimes called A system. These tubules enter the fiber usually at the edge of the A band. They have a diameter of $400-600$ $\AA$ and make contact with the elements of the sarcoplasmic reticulum in order to form diads. Diads usually occur at the edges of the $A$ band.
Secondly, the so-called $Z$ tubules. These are wider (ca. 800-1000 $\AA$ ) and enter the fiber at the $Z$ line. These tubules form only shallow incursions between the myofibrils and do not make contact with the sarcoplasmic reticulum. Along the $Z$ line the tubule stains densely. This mechanical fusion of $Z$ line material with the tubule suggests a supportive function. The function of the $Z$ system is supposed to be a contribution to the capacitance of the surface area of the muscle fiber. The $T$ tubules often have a longitudinal component (Atwood, 1971; Huddart, 1975).

In the Colorado Beetle, membrane invaginations are observed both on $\mathrm{Z}$ line level and on $\mathrm{I}$ band level. Invaginations on $A$ band level are seldom seen. Contiguity between a "T tubule" and an "I tubule" is observed. The diameter of a membrane invagination may vary, comprising the diameters of both $\mathbf{Z}$ system and $\mathbf{A}$ system as cited above. This leads to the conception that, in the Colorado Beetle, the membrane invaginations at the $\mathrm{Z}$ line and at the $\mathrm{I}$ band form part of one $\mathrm{T}$ system.

Desmosomes at the beginning of the $T$ system are described by Smith et al. (1966) in the muscle around the seminal vesicle of Carausius and by Toselli \& Pepe (1968) in the ventral segmental abdominal muscles of the bug Rhodnius prolixus. The function of the desmosomes in the $T$ system is undoubtedly a mechanical one, viz. furthering the cohesion of the muscle cell.

\section{The muscle attachment}

The attachment of the muscle sheath to the phragma between meso- and metathorax (figs. $7 \mathrm{~A}, 8)$ is essentially in accordance with former descriptions of muscle attachment (Auber, 1963; Lai-Fook, 1967; Koulish, 1973). Only the connection between the microtubules and the desmosomes deviates (Akster \& Smit, 1975).

The muscle attachment along the oviduct (figs. $16,17)$ deviates from all former descriptions of arthropod muscle attachment. There is no interdigitating desmosome border. Only a few short desmosomes are present between the muscle cells and thin processes of the epithelial cells. Hemidesmosomes, separated by a strip of basement membrane, are also less numerous and shorter than in the attachment of the outer ovariole sheath to the phragma. 
The epidermal cells of the common oviduct are different from all earlier described tendon cells. The microtubules get nearly lost amongst the great number of other organelles. Instead of the finger-like cuticular invaginations, a structure occurs, which is also observed on the apical border of chitin producing epidermal cells (Neville, 1975). In the adult animal the function as tendon cell is probably the main function of the epidermal cells of the phragma between meso- and metathorax. In the epidermal cells of the common oviduct the tendon function must be a secondary task. The major function of these cells is probably the production of chitin scales.

\section{The microtubules}

Microtubules are known to be involved in the changing of cell forms. Some observations suggest a passive role as cytoskeleton, other suggest an active role (Bloom \& Fawcett, 1968). There are also suggestions that microtubules are involved in the transport of water and small ions (Slautterback, 1963). Behnke \& Forer (1967) show that, within the same cell, four different classes of microtubules are present.

The occurrence of microtubules in the tendon cells suggests a more or less passive role as cytoskeleton. It is improbable that the microtubules in the terminal filament have a transporting function. The observed contractions in the terminal filament might indicate that the microtubules are able to contract and consequently would perform an active role in changing of form. The terminal filament, however, is surrounded by a muscle network. It is very probable that the observed contractions are caused by these muscles and that there is a passive cocontraction of the terminal filament.

\section{ACKNOWLEDGEMENTS}

The authors are much indebted to Miss. E. Velzing for her excellent technical assistance and to Mrs. G. Appel-Rijfkogel for typing the manuscript. The help of Mrs. A. van MarleMarschall in correcting the English text is also acknowledged.

\section{REFERENCES}

Akster, H. A. \& W. A. Smit, 1975. Bridges between microtubules and desmosomes in the terminal filament-cuticle connection and in the muscle-cuticle connection (tendon cell) of the Colorado Beetle (Leptinotarsa decemlineata Say). Neth. J. Zool., 25 : 122-124, figs. 1-3.

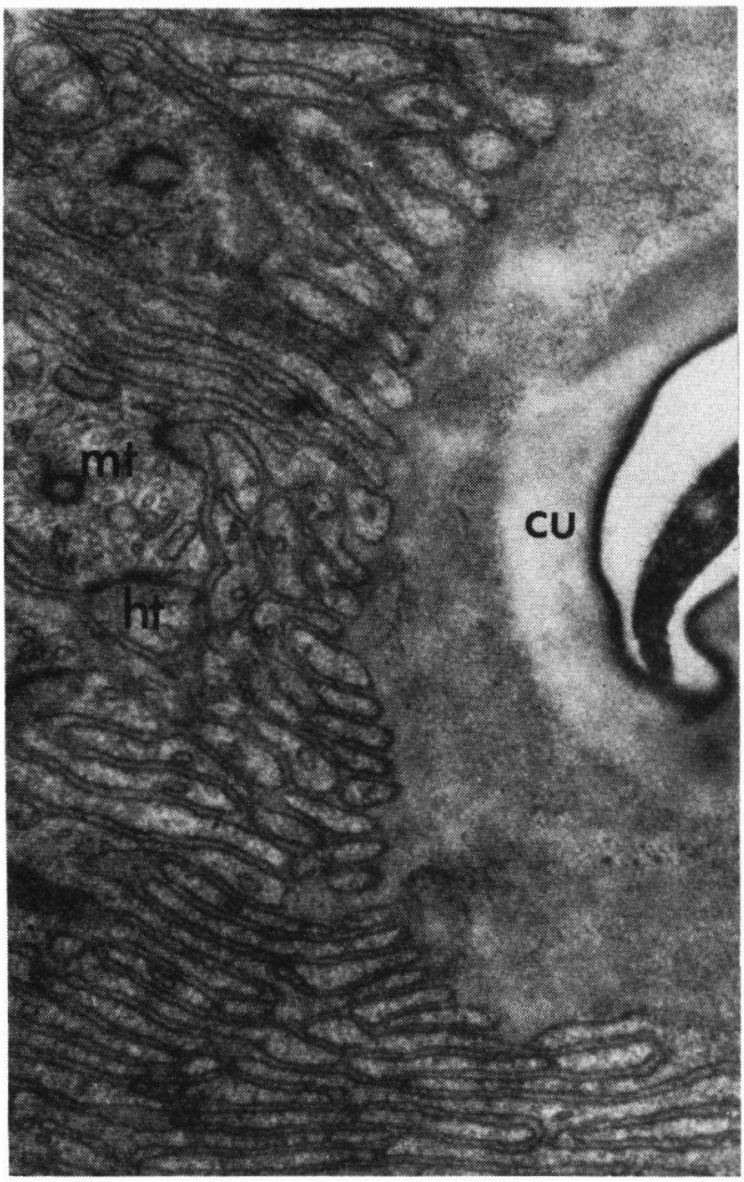

Fig. 18. Transverse section of the cuticular border of the epidermal cells along the common oviduct. Many narrow, parallel, anastomosing membrane invaginations occur. Some of these invaginations widen at their tops. Here the membrane shows a desmosome-like thickening. The dark line in the basement membrane, which is present in a hemidesmosome, is absent here. $41250 \times$.

$\mathrm{cu}=$ cuticle; $\mathrm{ht}=$ hemidesmosome-like thickening; $\mathrm{mt}=$ microtubules.

Ashurst, D. E., 1968. The connective tissue of insects. A. Rev. Ent., $13: 45-74$.

Arwood, H. L., 1971. $Z$ and $T$ tubules in stomach muscles of the spiny lobster. J. Cell Biol., $50: 264-268$.

AUBER, J., 1963. Ultrastructure de la jonction myo-épidermique chez les diptères. J. Microsc., $2: 325-336$.

BehnKe, O. \& A. Forer, 1967. Evidence for four classes of microtubules in individual cells. J. Cell Sci., $2: 169-192$.

BLOOM, W. \& D. W. FAwCETT, 1968. A textbook of histology (9th ed.): i-xvi, 1-858 (Saunders, Philadelphia/London/ Toronto).

Bonhag, P. F. \& W. J. ARnold, 1961. Histology, histochemistry and tracheation of the ovariole sheaths in the American Cockroach Periplaneta americana (L.). J. Morph., 108 : $107-118$. 
Chapman, R. F., 1969. The insects, structure and function: i-xii, 1-189 (English University Press, London).

Hehn, G. von, 1967. Die Muskulatur des Eileiters von Carausius morosus. I. Mitteilung histologische Untersuchungen. Z. Zellforsch., $78: 511-545$.

HuDDART, H., 1975. The comparative structure and function of muscle: i-viii, 1-397 (Pergamon Press, Oxford).

Iммs, A. D., 1970. A general textbook of entomology: $i-x i i$, 1-886 (Methuen, London).

JAhromi, S. S. \& H. L. ATwood, 1967. Ultrastructural features of crayfish phasic and tonic muscle fibers. Can. $J$. Zool., 45 : $601-606$.

King, R. C., S. K. Aggarwal \& U. Aggarwal, 1968. The development of the female Drosophila reproductive system. J. Morph., 124 : 143-166.

KoultsH, S., 1973. Microtubules and muscle attachment in the integument of the Balanidae. J. Morph., $140: 1-14$.

LAI-FooK, J., 1967. The structure of developing muscle insertions. J. Morph., 123 : 503-528.

Moulins, M., 1968. Étude ultrastructurale d'une formation de soutien épidermo-conjonctive inédite chez les insectes.
Z. Zellforsch., 91 : 112-134.

Neville, A. C., 1975. Biology of the arthropod cuticle: $-x v i$, $1-448$ (Springer, Berlin).

Noirot-Thimothée, C. \& C. Noirot, 1966. Attache de microtubules sur la membrane cellulaire dans le tube digestif des termites. J. Microsc., $5:$ 715-724.

Slautterback, D. B., 1963. Cytoplasmic microtubules. I. Hydra. J. Cell Biol., $18: 367-388$.

SMith, D. S., B. L. Gupta \& U. SMIтH, 1966. The organization and myofilament array of insect visceral muscles. J. Cell Sci., $1: 49-57$.

Snodgrass, R. E., 1935. Principles of insect morphology: i-ix, 1-667 (McGraw-Hill, New York/London).

Toselli, P. A., \& F. A. Pepe, 1968. The fine structure of the ventral intersegmental abdominal muscles of the insect Rhodnius prolixus during the molting cycle. I. Muscle structure at molting. J. Cell Biol., $37: 445-461$.

Truckenbrod, W., 1970. Ober die Oogenese der Termite Kalothermes flavicollis Fabr. I. Zur Feinstruktur des Terminal Filaments, Germariums und der Prophaseregion. Z. Zellforsch., 108 : 339-356. 